\title{
Infectious complications in heart transplant patients
}

\author{
Brînduşa Țilea ${ }^{1,2^{*}}$, Nina Șincu ${ }^{1,2}$, Simona Teches ${ }^{1}$, Mihaela Ispas ${ }^{3}$, Ioan Țilea ${ }^{2,3,4}$ \\ From The 10th Edition of the Scientific Days of the National Institute for Infectious Diseases "Prof Dr Matei \\ Bals" \\ Bucharest, Romania. 15-17 October 2014
}

\section{Background}

Up to $75 \%$ of the patients with heart transplant present signs of an infectious episode within the first year postheart transplant. Objectives: assessment of infections prevalence, correlation between cytomegalovirus (CMV) infection and post-transplant complications, occurrence of acute rejection and allograft vessel disease.

\section{Methods}

37 patients who underwent orthotopic heart transplantation have been followed for a period of five years. Posttransplantation screening has been performed over the following etiological agents: CMV, hepatitis B virus, hepatitis $\mathrm{C}$ virus, Epstein-Barr virus and Toxoplasma gondii. Receptors with criteria for CMV IgG and Toxoplasma IgG antibodies have been accepted. Infectious episodes at 1, 6 and 12 months and evolution depending on CMV screening results, correlated with infection, acute rejection and allograft vessel disease have been pursued. Microbiological techniques, echocardiography, chest X-ray and endomyocardial biopsy have been performed for diagnosis.

\section{Results}

The mean age of patients was 38.5 years. Within the range of 1 to 6 months, a number of 50 infectious episodes (IE) were identified, with an average rate of 1.35 IE occurrences per patient. After 6 months 68 IE were identified, with an average rate of 1.83 IE occurrences per patient. After 1 year, 22 IE were identified with an average rate of $0.59 \mathrm{IE}$ occurrences per patient. Following the correlation between CMV IgG antibodies after one year and bacterial infections, 2 pulmonary infections, 4 cases of upper respiratory tract infections, 3 cases of urinary tract infections, and one sepsis case were noted. Concerning the viral infections, out of the 26 patients with CMV IgG positive antibodies 16 (61.5\%) did not develop infections, 6 patients were CMV IgM antibodies positive, 3 were noted with viral pneumonia, 2 varicella zoster virus cases and one with herpes simplex virus infection were also found.

The correlation between the presence or absence of CMV IgG antibodies and rejection score has been followed. 9 CMV IgG antibody positive patients (34.6\%) had the rejection score 1,15 (57.7\%) were found with rejection score 0 . In CMV serology negative patients a 0 to 6 out of 11 rejection score (54.5\%) was identified. The four allograft vessel diseases recorded in the study group were found in CMV IgG antibodies patients.

\section{Conclusion}

During the evolution a decrease in survival rate related to CMV chronic infection has not been observed, but its role in the development of allograft vessel disease has been confirmed.

\section{Authors' details}

${ }^{1}$ Clinical County Hospital Mureş, Romania. ${ }^{2}$ University of Medicine and Pharmacy Tîrgu Mureș, Romania. ${ }^{3}$ Institute of Cardiovascular Diseases and Transplantation Tîrgu Mureş, Romania. ${ }^{4}$ Emergency Clinical County Hospital Tîrgu Mureş, Romania.

Published: 15 October 2014

doi:10.1186/1471-2334-14-S7-018

Cite this article as: Tुilea et al:: Infectious complications in heart transplant patients. BMC Infectious Diseases 2014 14(Suppl 7):O18.

\footnotetext{
* Correspondence: brindusa_tilea@yahoo.com

${ }^{1}$ Clinical County Hospital Mureş, Romania

Full list of author information is available at the end of the article
} 